\title{
Training \& Development Practices in National Bank of Pakistan
}

\author{
*Abdul Qayyum, Muhammad Tariq Sharif, Awais Ahmad, Murad Shuaib Khan, Kashif-ur-Rehman \\ Iqra University, Islamabad Campus \\ *qayuum_333@yahoo.com
}

\begin{abstract}
The purpose of this study is to explore the training \& development practices in National Bank of Pakistan (NBP). Different levels of officers are providing training \& development opportunities in NBP. Data collected from different staff colleges of NBP. Result of this study shows, bank is providing training \& development opportunities to its employees, but there is still gap which should be addressed. Training need analysis is not sufficient. Most of the trainers belong to operational background and they are unable to provide the sufficient training to develop the good employees. Bank does not have sufficient T\&D plan for the top-level management.
\end{abstract}

Key Words: Training \& Development, Human resource development, Training need analysis

\section{Introduction and Literature Review}

We are living in a global village where competition has been increasing among the organizations. To compete in this scenario, human resource is a key element of success. Organizations cannot get success until they have competent and developed work force. Human resourced development is the main function of human resource management. To get the competent and developed work force, organizations focus on management development. Training \& development programme are associated with perceived organizational support and job satisfaction. Providing the training and development opportunities to employee, it not only enhances the knowledge and skill of employee but also affect on the behavior of employee (Karl et al., 2010). Managers who intent to learn they achieve high competency level with developmental assignment. There is positive relation between developmental assignment and manager competency. Organizations have chances to increase the newly appointed manager's competency by developmental assignments. It is obligation of human resource department to plan such activities and assign developmental course of work to learning oriented managers to enhance their skill, knowledge and ability for the effectiveness of organization. Human resource department for achieving more competencies (Lisa et al., 2009) should also address managerial complexities.

Decentralized management development policy affects positively on performance. This is a useful tool for increasing knowledge, skill and ability of the employee. NBP has centralized policy. Problem of evaluation and accountability still exists in the policy. This policy is not compatible with goals of organization. The other problem is reactive policy. To overcome this problem organization has to be proactive for implementation and evaluation of management development policies. Operating in multi culture environment where there are many differences found in term of economic development. Therefore, different levels of management competencies are required to perform a job. To overcome this problem organization has to use global practices of management development, they use their policy only for guideline. National Bank management development policy should be aligning with corporate policy. Corporations should make their own management developmental policy to increase the competencies of their employees. Management development policies, at any level, should be evaluated and stand accountable. There should be clear understanding of policies goals, process and evaluation (Greg et al., 2009).

Development of staff has significant affect on the performance of employees, which, eventually, achieve the organization goal. Staff development provides opportunity to enhance the educational level through participating in different training courses, attending workshops and seminars. These things play a significant role in performance of employees to achieve the organizational goals. It is important for management to take 
keen interest in development of their employees and allocate sufficient budget for this purpose. These practices can be use in staff development of other professionals (Frederick and Stephen, 2010).

There is a positive relation found between human resource (HR) development and other human resource function. Therefore, organizations have to focus more on all HR practices to achieve the individual and organizational goals. Organizations have to focus on human resource practices, policies and strategies, which enhance skill, knowledge for the career development of the employee (Kate et al., 2009). Working in an international organizational, it is important to learn about the culture of organization and culture of society of that country. Organization tries to develop their employee to meet the requirement of the culture. There are different ways to develop the employee. It is important for managers to achieve the maximum awareness about the community and culture of the organization. Practical experience is most convenient way for the development of employee in this scenario. It is compulsory for those employees who are working in multinational organization to get training about culture and the environment of host country. Due to globalization of world, it is also necessary to get skill, knowledge and ability about the cross-cultural differences for efficient working in international organization (Brian, 2011).

Training practices adopted by public sector organization impact on human resource management function in many organizations from last decade. These training practices lead the organization to develop their employee. Training and Development also integrate entire practices to involve more strategically in human resource management. Research shows that training play a significant role in the execution and planning of human resource management. Implication for this public policy for the development of employee is more important. Training has significant importance in human resource management in many corporations (Andrew \& Erica, 2007). In Banks, training and development practices considered best practices. Banks try to pay more attention on training and development to meet the future human capital need. They, not only, provide on the job training, but also plan formal training and development programme to get maximum competitive workforce edge. They are willing to have a skilled and well-trained workforce. Banks not only train their workforce for short-term needs but also develop their employee to meet the future challenges. Organizations invest in training and development, which relates high committed HR practices. T\&D leads the workforce to accomplish the organization goals. This is just because of formal and informal training. Banks build strong relationship with their employee, conducting training and development programmes. They trust their employee, empowered them to get maximum output from its workforce (Olivia and Leonidas, 2010).

For the career development needs, banks have to provide many services relating to adoption of new technology and human resource practices. Organization and career center professionals provide proper training and development facilities to ensure the competent workforce that will be available at time of need, although they have limited resources. Need assessment is very important for decision making in this case. It should involve all stakeholders. Effective use of new technology, it is very important to provide training and development (Melissa, 2010). From the initial survey, the outcomes of training across this area of banks were mostly unknown and unmeasured. Previous results shows that indicated even in the large banks, $60 \%$ of training budget lack quantifiable target to achieve. In banks, skill needs are different as compared to other firms (Keith, 2011). Training needs analysis is very important element of training and development. There are nine different areas of human resource management and human resource development for training need analysis, which are training plan, goal setting, employee development, managing change, career development, knowledge, skill, ability and attitude towards learning and motivation. While studying training need analysis, we focus on what is happening and what should be happen. In this study, we evaluated the relation of training need analysis with human resource management and human resource development. We have come to know that training and development modifies the behavior of employee towards organizational goals. We can increase the motivational level of employee through training need analysis (Iqbal \& Khan, 2011).

Becoming the market leader in providing services it is important for organization to train and development their staff. Making training and development strategies, organizations have to given proper attention in implementation and evaluation. Effective training and development strategies increase the knowledge, skill and ability of employees. Vision is very important for achieving effectiveness and it should be clear to all employees. Institutions that train, develop and retain their employees are more committed with training and development. It is important for HR to make sure that the strategic development plans are align with the 
organizational vision, mission and objectives. It is also important for organization to develop integrated training and development, knowledge sharing culture in organization to achieve the organizational goal. Effective communication and performance appraisal play also a significant role in employee development and organizational objectives (Naris and Ukpere, 2009). Research shows that if an organization provides significant training and development programme, it decreases conflicts among employees. The ratio of employee's conflict is less in those organizations, which have sufficient training and development programme. We are living in the era of computer but the development of staff is more important for achieving the effectiveness and profitability of organization. It generally accepted that organization has to invest heavily in training and development. Some organizations take it as expense, but research shows that training and development is an investment and not an expense. Without investment, we are unable to get profit. No organization can achieve competitive edge without training and development. Training is expensive but without training is more expensive (Oluseyi, 2010).

Most of the training and development programmes enhance the professionalism among the employee and meet the expectation of employees. Organizations convene the training and development programme for the development of their staff. Employees have opportunity to develop themselves, enhance their skill and ability through these development activities (Bernice, Sweden and Birgitta, 2011). Assessment of knowledge and skill is very important for evaluating outcomes. Motivation has positive impact on learning. Therefore, we encourage our employee to be prudent in their self-assessment knowledge as cognitive learning outcomes also considering the learning environment. We have to encourage future research on the self-assessment process and how educators and trainers can build accurate self-assessment that promotes lifelong learning (Traci and Katherine, 2010). This study is about the training and development practices at National bank of Pakistan. NBP established in 1949 to provide the banking facilities to both public and private sectors. It is playing a phenomenal role in the growth of economy of Pakistan. To compete globally bank have well known about the importance of its employee. To provide comprehensive training \& development opportunities to its employee, the bank has established four staff colleges. These colleges are providing training and development facilities to employees. Different categories of employees are trained in Staff College. NBP plan a training catalogue for training purpose. Different operational and behavioral training are plan in this catalogue.

\section{Methodology}

This study is about the training and a development practice in NBP. Quantitative data collected from staff colleges of NBP. NBP has developed a training catalogue for conducting training and development at its staff colleges. In the training catalogue of NBP, nine areas selected for training. Training catalogue contains general banking operation / foreign exchange, regulatory compliance, Islamic banking, marketing and banking relationship, management development programme, communication skill, information technology, operation/ foreign exchange management courses and others. Four levels of employees are selected for training that is: executives, officers grade I, II and III. These officers provided with training in different areas, which mentioned in training catalogue. Different statistical tools used in this study for analyzing the data. Pivot chart, histogram and simple correlation are use in this study.

\section{Discussion and Analysis}

National bank of Pakistan is providing training and development opportunities to its employee through their staff colleges. The inferences drawn from analysis of quantitative data as well the qualitative observations presented as under.

Training in Management Development programme: Training and development programme for the development of employee is very important area for training need analysis. In NBP, training and development practices are considered best practices. Banks try to pay more attention on training and development to meet the future human capital needs. They not only provide on the job training but also plan formal training and development programme to get maximum competitive workforce edge. They are willing to have a skilled and well-trained workforce. Banks not only train their workforce for short-term need but also develop their employee to meet the future challenges as well. Organizations invest on training and development, which relates high committed HR practices. It leads the workforce to accomplish the organization goals. NBP 
provide training in leadership skills, Stress management, time management, team Building, personality and attitude development, human resource management and development, change management, performance management, talent management others. These areas are very important for the development of employees. Bank is providing off the job training to their employee in different staff colleges. Some important inferences management development practices drawn from figure 1.

Figure 1: Management Development Practices in NBP

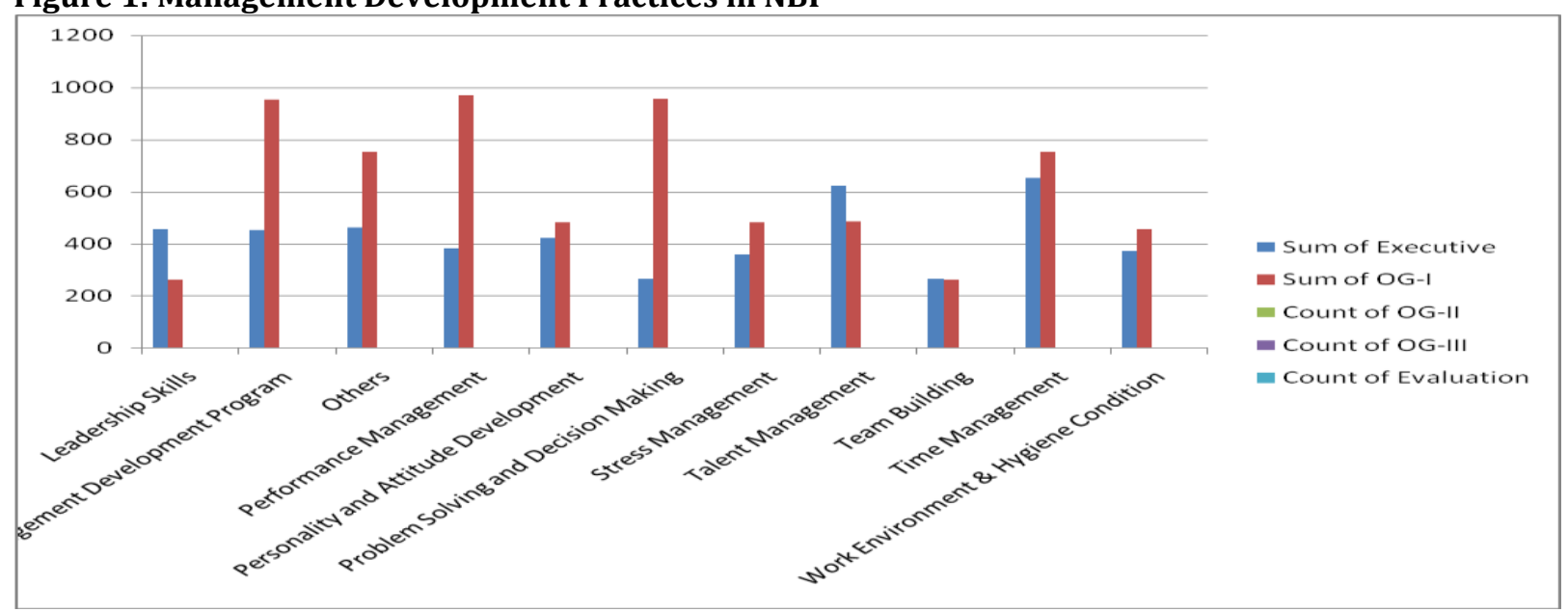

In this figure officer grade one are provided more training as compared to other officers. Officer's grade I am provided more training opportunities in management development programme, performance management and decision-making. Executive provided more training in leadership skill, talent management and time management as compare to other areas. Officers grade one and three not provided the management development training. Evaluation is most important step in training deliverables. However, we see in figure that no evaluation has made after providing the trainings. Without the evaluation of trainings, the organizations are unable to achieve the objective of trainings. The ratio of officer grade "I" is more than the executive in management development training program. These training provided for the period of one or three days which is not sufficient for achieving the training objectives. Eight hour training is provided to the employee in the staff college, which could not cover the completely training module. In table 2 the average is between 200 and 600 that officer are provide training and development opportunities of officer grade one and executive. The areas, which a covered in this graph, show conflict management, human resource management, goal setting and change management. This figure also shows that no evaluation has made while providing the training and development. Training provided by bank in the area of management development covers the mostly management development but there is more need of training need analysis to provide the training in other remaining areas like organizational citizenship behavior organizational commitment and diversity management. The trainer would be also the human resource expert.

\section{Figure 2: Management Development Practices in NBP}

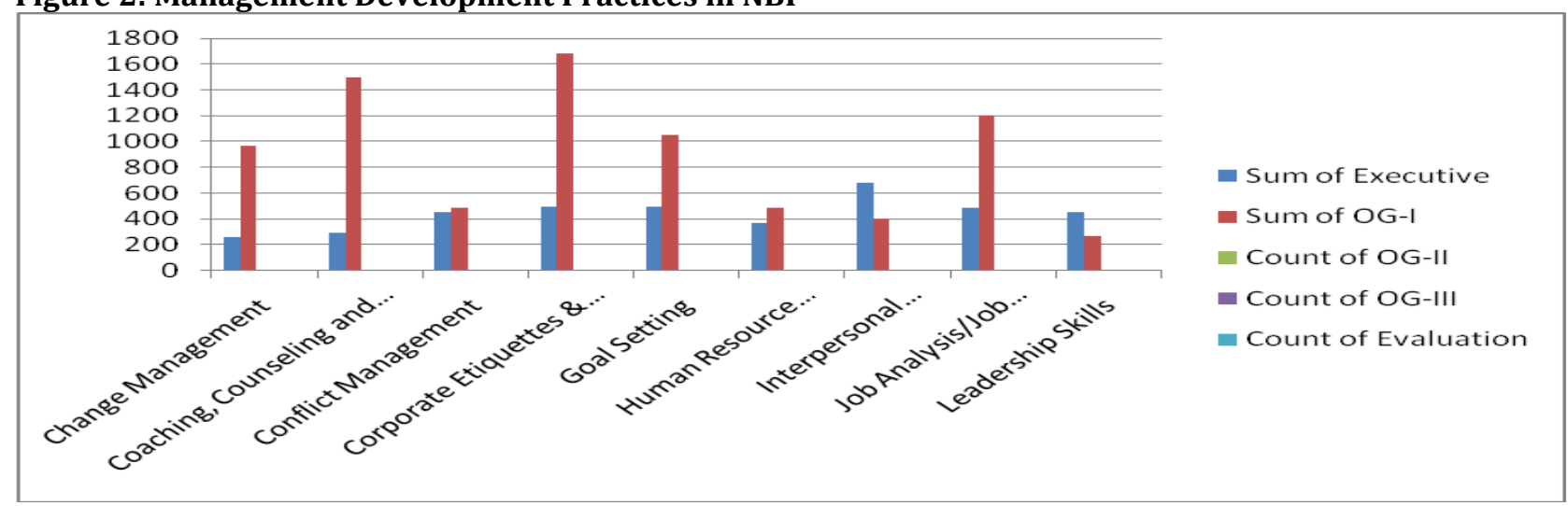


Training in general banking /operation/credit and foreign exchange: National bank of Pakistan provides training to their newly employed staff and officer in the field of general banking. Sixty nine areas are selected for general banking operation training. Some of the areas are Opening, operations and maintenance of current PLS saving, PLS term deposit, call deposit and other accounts, payment \& collection of cheques - legal implications, remittances and collections, working of cash department, safe custody \& safe deposit lockers, pension payment services, management of currency chest, government receipts and payments, Federal Board of Revenue (FBR) Collections, branch accounts, branch returns, inter branch reconciliations, Hajj Services, ATM operations, branch HR Functions dead stock, stationery, vouchers, filing and record management, branch internal controls and compliance, dealing with internal audit and SBP inspections, branch security branch assets and information security management, disaster recovery plans, NBP product line and services, KYC, Anti Money Laundering (AML) and constituents accounts, branch operations management, business development strategies, bank's vision, mission and core values, credit policy and manual, securities and collaterals against loans, asset products. One or three days training provided in the different staff colleges. Mostly, officer grade II and III provided training in general banking practices and day-to-day operation.

\section{Figure 3: Training in General Operation/Function}

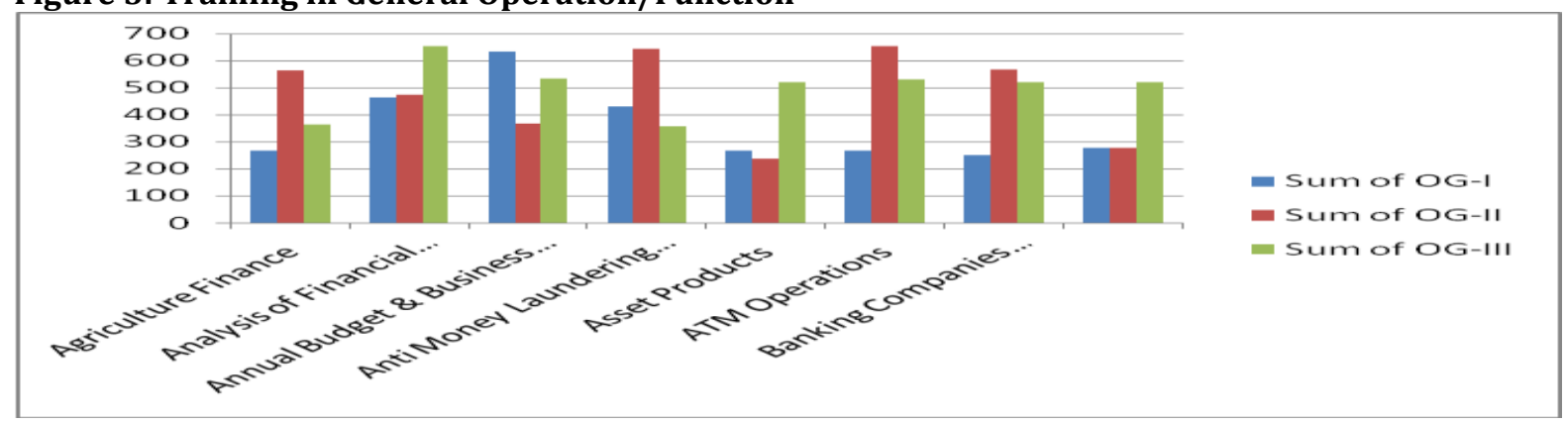

\section{Figure 4: Training in General Operation/Function}

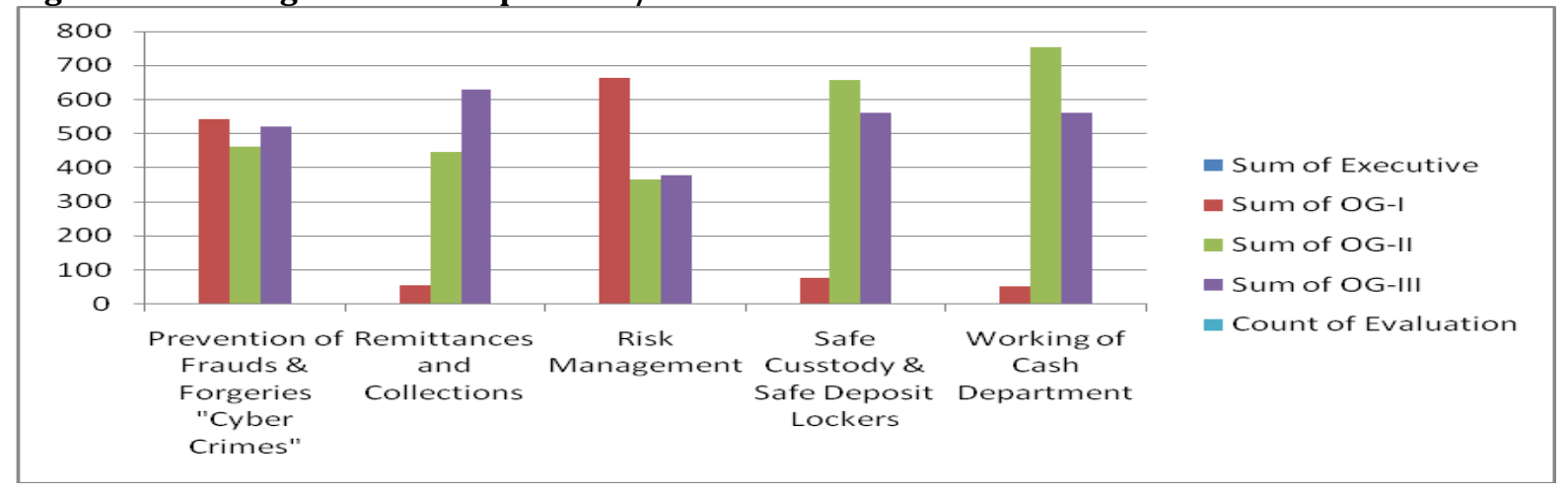

Figure 5: Training in General Operation/Function

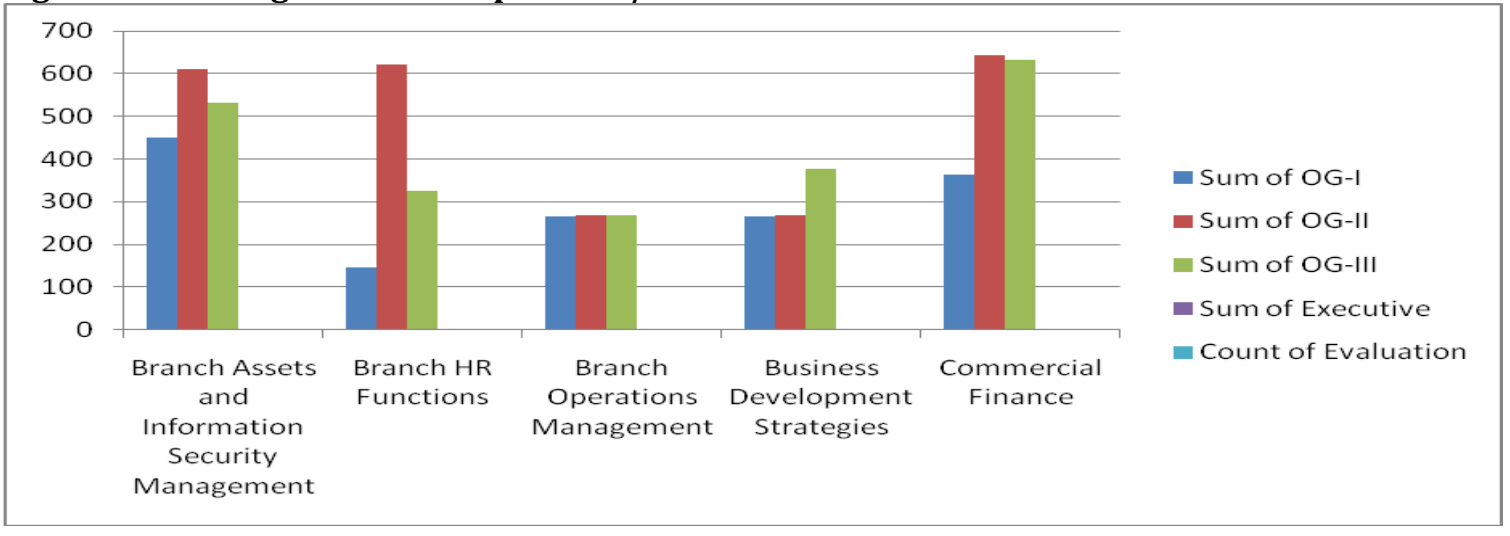


Figure 3, 4 and 5 shows that three level of officer are provided the general banking and operation training. A large quantity of officer belongs to grade III and II. Some oficer grade I are also provided training in this area. As this is the general banking and operation training programmes, therefore, no executive is selected for the training in this area. Evaluation which paly a significient role in achieving the objective of trainig \& development. Management development policy and data show that there is no evaluation is being made to judge the training effectively. Mostly training are provided from eight hours to twenty four hours. Randomly people are selected for training, They came in the staff college for one or three days and attend the trainig class. Further no evaluation result. In general banking the selected areas are more that slected time for providing training. Some other people are provided trainig also in general operation banking of national bank.

Regulatory compliance: To give the comprehensive trining in about the rules, procedure and laws national bank has selected fourteen areas of training. Although officer are also get information aobut the new rules and regulation from the circular but bank arranges the training session for this also.

\section{Figure 6: Regulatory Compliance}

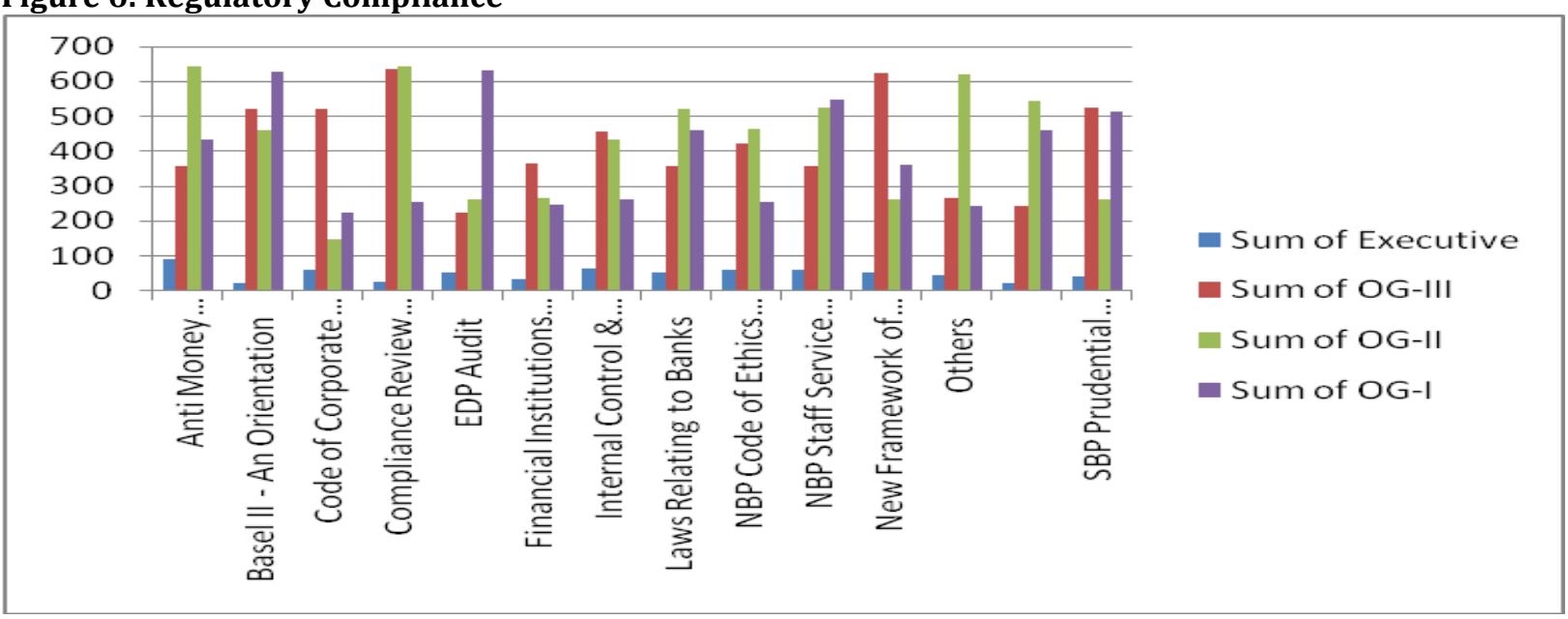

Figure 6 shows that training about the regulatory compliance is provided four level of officers. Minor quantity of executive are provided training in this field but the quantity of officer grade I,II ,III is more. While the need analysis banks has cover to provide extensive training in the field of regulatory compliance. They have tried to covered all the compliance areas which are necessary for a bank officer.

Islamic Banking: Now a days trends has been changed in islamic banking. More customer are interested in islamic mode of finance. The islamic banking is rapidly getting apprecation in the world. National bank of Pakistan has also started operation in islamic banking. For this purpose the need of trained workforce has increased many folds.. NBP is providing training in islamic banking to its employees. Four areas of training are slected by bank to provide training which are not enough.

Figure 7: Islamic Banking

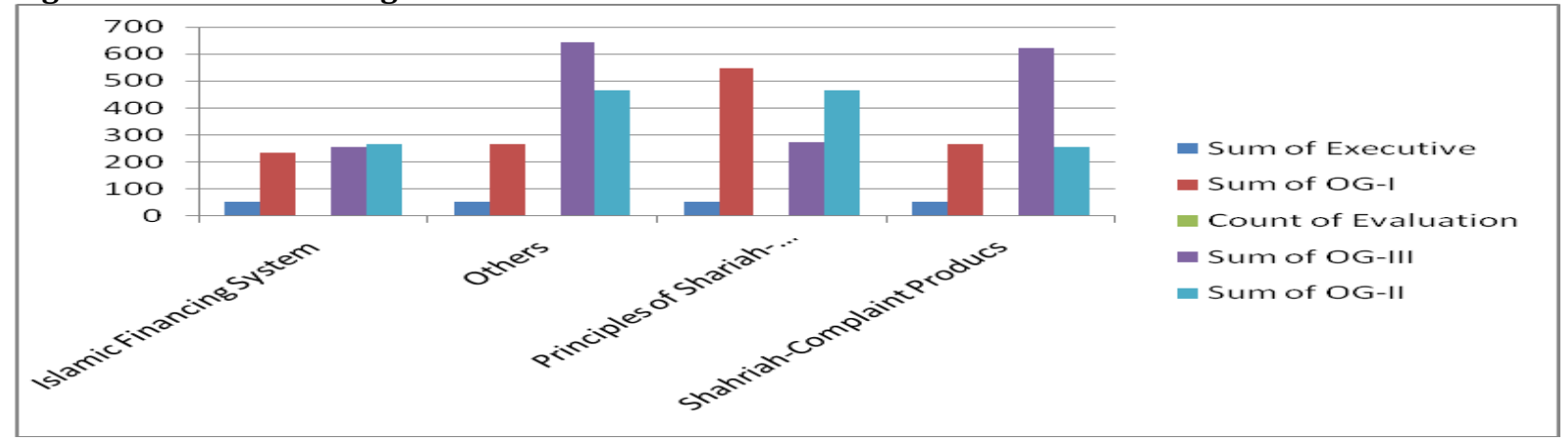


Above figure show that the trainig provided about the islamic banking. Keeping in view the size of organization the number of employees who are provided training in islamic banking are not sufficient. A minor quantiy of executive is provided such trainig in this critically important area. Graph also shows that there is no evaluation record of this training. It is therefore bank has to choose more areas of islamic banking for training. The bank has to focus training needs analysis that what kind of islamic banking training is required for effective operation. Islamic banking expert should train in this area instead of formal trainer.

Traing in Information Technology and Computer: In recent years, the utilization of information technology has been magnificently increased in service industries, particularly, the banking industry, which by using Information Technology related products such as internet banking, electronic payments, security investments, information exchanges, financial organizations can deliver high quality services to the client with less efforts. To provide the good customer services and to perform job efficiently with information technology trainings of employees are most important. NBP has selected nineteen areas of information technology for providing training.

Figure 8: Training in IT

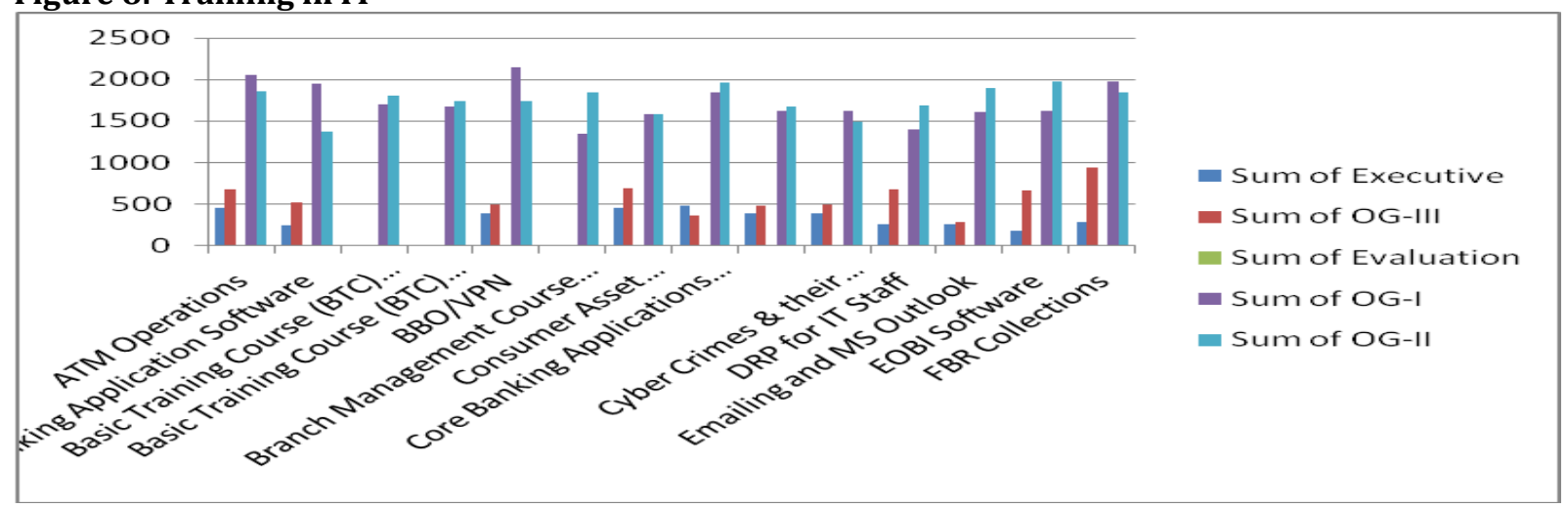

Above figure shows that officer grade I and II are provided more training in the field of information technology. Quantity of officer grade III and executive are provided less trainig in this field. Training provided in IT is not meet the current requiremnet of need. The people who have experience above eighteen years are not will to get the training of information technology. The bank have to change their managemnt development policy for changing the old culture. New and energetic people should be employee to use the IT for the effectiveness of the organization. IT expert should be outsource for the providing the traing inspite of operational trainer.

Training in foreign Exchange: National bank of Pakistan is also providing training in foreign exchange

Figure 9: Training in foreign Exchange

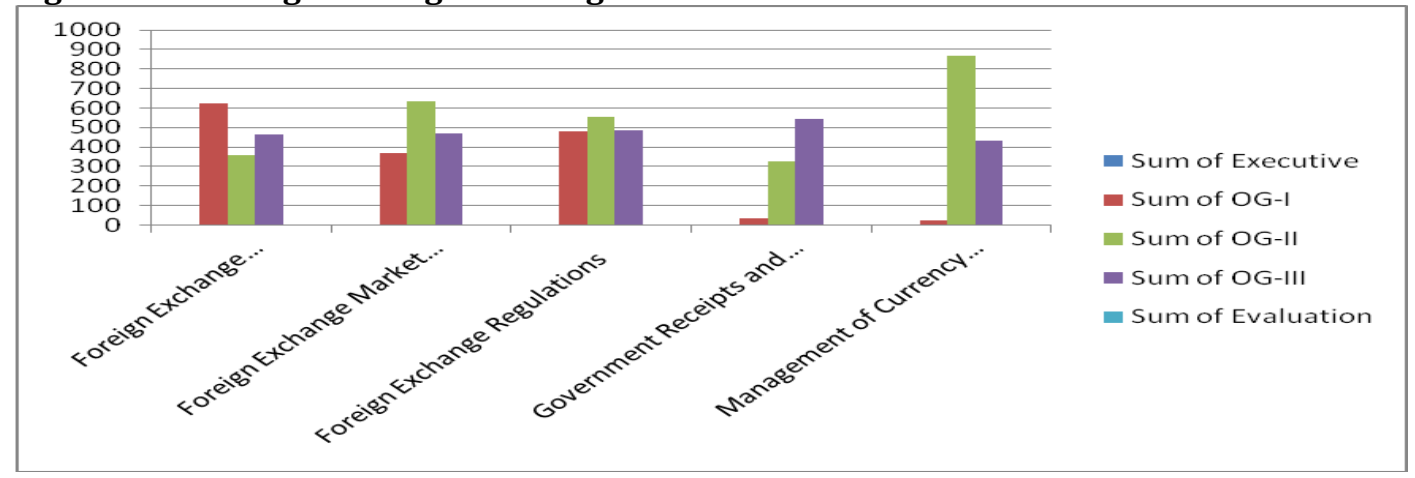


Above figure 9 shows that bank is providing extensive training in foreign exchange and foreign exchange market also. Officer grade I, II,III are provided training in this field to deal with the different forign exchange and other international financial matters.

OPERATIONS/CREDIT/FOREIGN EXCHANGE \& MANAGEMENT COURSES (LONG DURATION PROGRAMS): These programme are offered for one to five weeks duration. These programme are arrange for enhancing the competenciaes among the officcer. In this area different programme are for the development of executive or to trained the newly fresh trainee. Different twenty five areas are selected in this field.

Figure 10: OPERATIONS/CREDIT/FOREIGN EXCHANGE \& MANAGEMENT COURSES (LONG DURATION PROGRAMS)

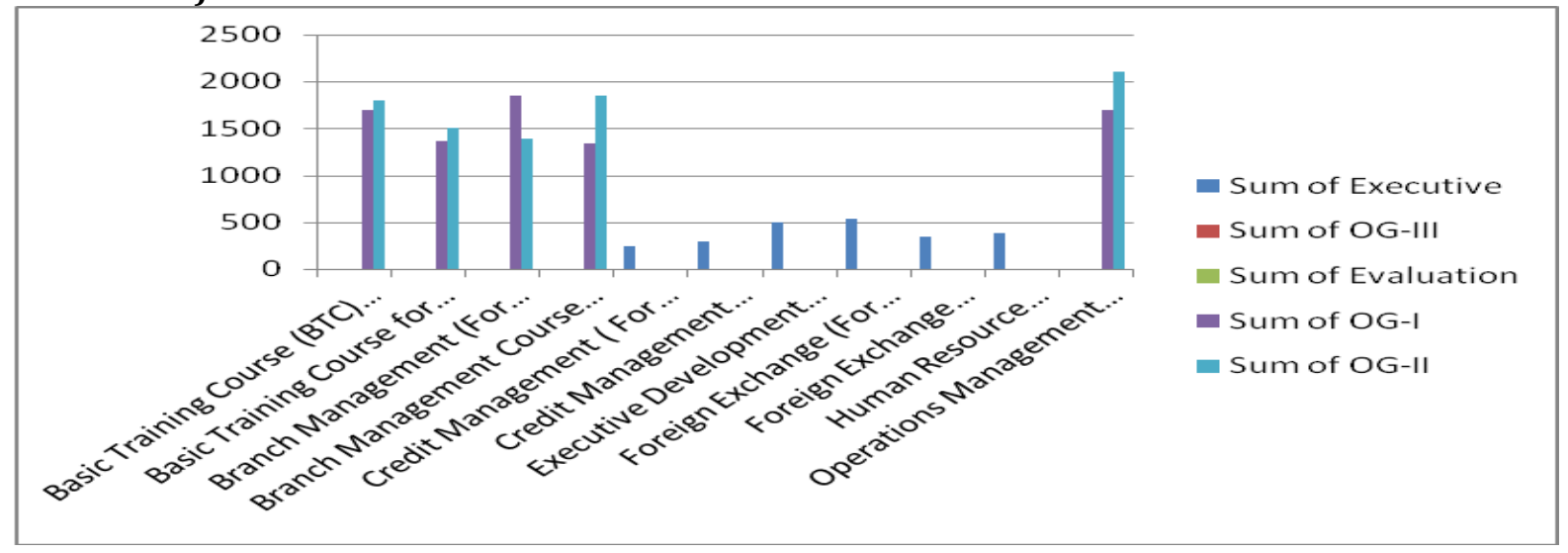

These long term courses are provided training to newly appointed officers or the devleopment of executive. These long courses are provide for the one week to one month but the no evaluation has been found in these long course also. Officer join the course for specified time, Some officer take no interest in these courses they just join for allowances. No further training and development audit has been conducted for evaluation. Although these programme are provide extensive knowledge but there is still need to improve our human resource management strategies to get the maximun out put from the training and development activities.

Discussion: There are different types of training programmes that are being conducted by the "Training And development department".These different programmes are training in management development programme,training ingeneral banking/operation/credit/foreign exchange , regulatory compliance , training in information technology and computer, and training in operations/credit/foreign exchange and management cources(long duration programmes). Training in management development programme consider the couple of areas that leadership skill ,stress management, talent management ,time management, and work environment and hygiene condition etc.OG I grade officers are main beneficiries of trainings under this head but excutive are at top in leadership skill ,talent management and time management trainings and all these trainings are very relevant to them also .Training in general banking/operation/credit/foreign exchange are related to the operational activites of the bank to perform their job.That training is about the operational needs of the job and because of that it is very relevant for the grade I and II officers but least relevant for the excutives.

Regulatory compliance training is about the rules, procedures and laws of national bank.It is very relevant for grade I,II and grade III employees but least relevant for excutives of the bank.Islamic banking is becoming very relevant in pakistan now a days.Areas of islamic banking and employees that got benefit from that training are not sufficent though "islamic banking " is very broad field.Training in information technology and computers is not sufficent to full fill the current needs. They focous grade I \& II employees in the IT training but massive advancement and dependence of banking system on IT ask to make IT training more extensive and also broaden the area also from employees point of view.Operations/credit/foreign exchange and management cources training is extensive training programme from one week to one month. That is normally for excutives to train them according to their business and human resource strategies. There is lack of modern 
evalution system to measure the effectiveness of the trainings .Lack of personal individual record regarding their individual strength and weeknessess.Lack of individual personal record ,selection for the trainings are made randomly with out any systematic calculation. Time span for several important trainings are very short.

\section{Conclusion and Recommendation}

Human resource management play a significient role in the effectiveness of the organization. Without the human resource practices no organization gets the competitive advantage which is mostly required. Training and deveopment is the important function of human resource management. Training is provided to enhance the skill, ability and modify the behavior of employee to achieve the organizational goals. National bank of Pakistan established in 1949 to provide the banking facilities both public and private sectors. It is playing a key role in the growth of economy. To compete globally bank is well known about the importance of its employee. To provide comprehensive training \& development opportunities to its employee bank has establish four staff college. These colleges are providing training and development facilities to employees. Bank has developed the training catalogue for training the employee. One hundred sixty seven areas selected for training in the field of general operation, regulatory compliance, Islamic banking, management development, IT and general operation long courses. After analyzing the data of training, we have found that there is no proper training need assessment. Employees selected randomly for the training. They provide training according to their developed catalogue.

Bank does not focus on the skills of employee. If an employee has good skill in general operation, bank is providing training to him instead of those employee have need to his training. There is no analysis of skill, ability of the employee that what kind of training is required to boost the performance of the employee. For the effectiveness of training bank has to change its training need analysis method. Research shows that there are nine areas of training need assessment, which should consider while developing the training plan. There is no evaluation of training and development programme. Bank providing the training but did not evaluate the training. After training authorities are unable to judge the skill, knowledge and ability, which are increase during the training. Some of the employees considered training as burden. Therefore, for the effectiveness of the training and development programme bank have to start the evaluation of the employee before the training and after the training to know that how much skills, knowledge has been increase after the training.

There is no alignment of training \& development strategies with the over all strategies of bank. Bank has to align its training strategy to its vision and mission. Training audit should conduct to know the effectiveness of the training. Only four level of officer considered for training and development, other level should also be provided training. Bank is providing training on the reactive approaches but for achieving the ultimate objectives, it provided of the proactive basis. Training should provide in all human resource areas to increase the efficiency of employee. The human resource expert should provide one another important thing is that human resource training. The most important thing that is missing in the training of bank is the management of diversity. Bank is operating in Pakistan and other countries, so it is necessary for authorities to provide the diversity management training to its employee for the smooth function of the work. Head of training and development department should be a human resource expert. To sum up the study, national bank is providing the extensive training to its employee. There is need of improvement in few areas in especially in the field of training need analysis. Globally training need analysis practices should be used. Evaluation must be place for the effectiveness of T\&D and bank performance. There is also need of management commitment for providing effective training. Future study can conducted on the training and development practices in any other bank or organization.

\section{References}

Andrew, S. \& Erica, S. (2007). The Role of Training in the Development of Human Resource Management in Australian Organizations. Human Resource Development International, 10(3), 263-279.

Bernice, S., Sweden, U. \& Birgitta, L. (2011). Different development programmes - does it make a difference? Leadership in Health Services, 24(1), 29-50.

Brian, J. H. (2011). Simulation training methods to develop cultural awareness. Journal of industrial and commercial training, 43(4), 199-205. 
Frederick, B. J. A. N. \& Stephen, O. O. (2010). Teachers' perceptions of staff development programmes as it relates to teachers effectiveness: A study of rural primary schools in Kenya. Educational Research and Review, 5(1), 001-009, 12.

Greg, G. W., William, J. R. \& Judy, Y. S. (2009). Management development in China: a policy analysis. International Journal of Training and Development, 13(4), 1360-3736.

Iqbal, Z. M. \& Khan, A. R. (2011). The growing concept and uses of training needs assessment: A review with proposed model. Journal of European Industrial Training, 35(5), 439-466.

Kate, H., Cherrie, J. Z., Brian, K. C., Yiming, Z. \& Sijun, S. (2009). Perceptions of the effectiveness of training and development of 'grey-collar' workers in the People's Republic of China. Human Resource Development International, 12(3), 279-296.

Karl, P., Alan, C. \& Nigel, G. (2010). Formal Development Opportunities and Withdrawal Behaviors by Employees in Small 281-30.

Keith, B. (2011). The challenges for sustainable skills development in the UK automotive supply sector: Policy and implementation. Management Research Review, 34(1), 133-147.

Lisa, D., Paul, E. T. \& In-Sue, O. (2009). Understanding managerial development: Integrating developmental assignment, Learning orientation, and access to developmental Opportunities in predicting Managerial competencies. Academy of Management Journal, 52(4), 731-743.

Melissa, A. V. (2010). Using Technology to Deliver Career Development Services: Supporting Today's Students in Higher Education. The National Career Development Association, 59, 87- 93.

Naris, S. N. \& Ukpere, W. I. (2009). The effectiveness of an HR code: Staff development and training at the Polytechnic of Namibia. African Journal of Business Management, 3(12), 879-889.

Olivia, K. \& Leonidas, M. (2010). Training and development in British hospitality, tourism and leisure SMEs", Managing Leisure ISSN 1360-6719 online \# 2010 Taylor \& Francis.

Oluseyi, A. S. (2010). Influence of workers' training programmes on conflict reduction in industrial organizations in Nigeria. African Journal of Business Management, 4(7), 1240-1246.

Traci, S. \& Katherine, E. (2010). Self-Assessment of Knowledge: A Cognitive Learning or Affective Measure? Academy of Management Learning \& Education, 9(2), 169-191. 